Article

\title{
Assessment of Climate Change Sentiment, Engagement and Adaptation through a Community-Based Outreach Campaign and Questionnaire across the United States
}

\author{
Shahir Masri ${ }^{1, *}$, Athina Simolaris ${ }^{2}$, Suellen Hopfer ${ }^{1}$ and Jun $\mathrm{Wu}^{1}$ \\ 1 Department of Environmental and Occupational Health, Program in Public Health, University of California, \\ Irvine, CA 92697, USA; shopfer@hs.uci.edu (S.H.); junwu@hs.uci.edu (J.W.) \\ 2 School of Education, University of California, Irvine, CA 92697, USA; Athina.Rise@gmail.com \\ * Correspondence: masris@uci.edu
}

Received: 24 October 2020; Accepted: 16 November 2020; Published: 17 November 2020

\begin{abstract}
Background: Human activity is warming the planet and destabilizing the climate through greenhouse gas emissions, which underscores the need for climate communication to overcome barriers to action. (2) Methods: We launched a five-month campaign that included questionnaires $(n=500)$ and one-on-one interviews $(n=24)$ to assess climate change sentiment, engagement, adaptation, as well as understand who climate outreach reaches and the observations and concerns such groups report across the U.S. so as to better understand the local context of climate change and enable more effective climate communication and outreach in the future. (3) Results: Results showed outreach efforts to mostly reach college educated Caucasians who identified as Democrats. "Future generations" was the most frequently ranked climate concern, with the economy, property value, and national security ranked last. Communities frequently observed hotter temperatures, increased flooding, and species impacts. Among "climate-concerned" individuals, the majority reported never contacting a local politician about climate change. College students least frequently reported climate change as a top priority and reported a low frequency of civic engagement on the issue. In-person interviews highlighted climate impacts disproportionately affecting low-income communities and communities of color, such as heat-related mortality and gentrification. Climate adaptation strategies were underway, but mostly among farmers, ecologists, and non-governmental organizations (NGO) workers. (4) Discussion: This study helps inform elected officials, urban planners, and climate communicators as it relates to the allocation of resources for climate adaptation and education, and highlights key knowledge gaps that deserve focus by future outreach efforts.
\end{abstract}

Keywords: climate change; global warming; questionnaire; climate communication; climate survey

\section{Introduction}

Carbon dioxide $\left(\mathrm{CO}_{2}\right)$ and other greenhouse gases (GHGs) are accumulating in the atmosphere due to human activity. According to the Intergovernmental Panel on Climate Change (IPCC), global net human-caused emissions of $\mathrm{CO}_{2}$ would need to fall by $45 \%$ below 2010 levels by 2050 in order to keep global warming below $1.5^{\circ} \mathrm{C}$ relative to pre-industrial temperatures [1]. Warming of $1.5^{\circ} \mathrm{C}$ or more is expected to "increase the risk associated with long-lasting or irreversible changes", such as the loss of some ecosystems, according to the report. Thus, immediate transformations in energy, land use, buildings, transportation, and cities are required to curb GHG emissions and slow climate change.

As the second leading global emitter of $\mathrm{CO}_{2}$, the U.S. has an important role to play in reducing emissions and thereby limiting further warming. Yet, according to the Fourth National Climate 
Assessment, mitigation and adaption efforts are inadequate and insufficiently scaled to avoid substantial damages to the U.S. economy, environment, and human health [2].

While the United States has accounted for a substantial fraction of global GHG emissions to date, there has been a division among American policymakers that has stalled the adoption of needed climate mitigation policies and adaptation strategies. Some of this divide exists in the American public as well, although research and polling suggests that the public divide is exaggerated [3]. Particularly in recent years, the proportion of Americans reporting concern about global warming has grown. A recent Gallup poll found that approximately $45 \%$ of Americans "worry a great deal about global warming" [4]. Additionally, a 2019 survey of over 1300 people found that $52 \%$ of Americans are "extremely" or "very" sure that global warming is happening, an increase of $15 \%$ compared to four years prior [5].

In the U.S., recent national polling has shown Hispanics/Latinos (69\%) and African Americans as (57\%) more likely to be "alarmed" or "concerned" about global warming, compared to $49 \%$ of Whites [6]. Hispanics/Latinos (11\%) and African Americans (12\%) were also less likely to be "doubtful" or "dismissive" of anthropogenic climate change compared to Whites (27\%). Nonetheless, the U.S. falls below the global median when compared to other parts of the world in terms of the population reporting that climate change is a "very serious" problem [7]. According to a 2018 poll, only $46 \%$ of American's believe that climate change should be a top policy priority for the federal government [8].

Given the dramatic and widespread climate impacts projected to occur by the end of this century, a number of efforts have been made to help mobilize the public and policymakers to support climate change mitigation and adaption policies [9-11]. Despite these efforts, major national- and state-level GHG emissions regulations have yet to gain support, and are seldom discussed during political campaigns and televised debates [12,13].

Explanations for the lack of widespread public mobilization around climate change in the U.S. are multifarious. One explanation may relate to its perception as an abstract, complex, and distant problem, since human nature responds mostly to perceived threats that are proximal and immediate [14]. Another explanation may be that climate communicators are not properly framing the problem so as to engage communities of diverse social and economic backgrounds [15]. Additionally, political affiliation has been shown to strongly correlate with people's perspective on climate change $[8,16]$. Studies have shown that this association exists, and can even become more polarized among individuals who are more educated, showing increased concern among highly educated Democrats and reduced concern among highly educated Republicans [17-21]. The increased dissemination and availability of spurious online information, which can enable major confirmation bias, or "echo chambers", is likely contributing to the increased polarization and politicization around the topic.

Though some research shows no association between general science literacy and concern about climate change, it is nonetheless reasonable that more specific knowledge about climate science is predictive of a person's views on climate change [20,22]. A contributing factor to the lack of mobilization around climate change may, therefore, relate to the paucity of climate-related education that most people receive. Moreover, consumption of science news among the public has decreased over the years as has the number of journalists focused on environmental reporting [23]. The notion that more knowledge can affect climate concerns is supported by research showing that people who scored higher on a quiz assessing climate-related knowledge tended to express greater concern regarding climate change consequences [24].

To date, a variety of strategies have been employed to raise public awareness about climate change. These include efforts by non-profit, public health and environmental organizations (e.g., Citizens' Climate Lobby, 350.org) as well as national and international governmental and non-governmental organizations (NGOs), some of which were founded with the sole purpose of addressing climate change [25-29]. These have included trainings and workshops to create "climate leaders", as well as conferences and community presentations to raise awareness about climate change and energy conservation. Despite these efforts, the United Nations Environmental Programme notes that "the scale 
of the change required . . . and the vast number of people and interests that must be influenced, calls for outreach activities of a much greater magnitude".

As needed climate outreach efforts are developed to raise public awareness, it is important to understand the efficacy of different outreach strategies and the audiences at which they are targeted so as to better inform and prepare future climate communicators and outreach efforts.

In this study, we used both quantitative and qualitative methods to describe results from a five-month national outreach campaign that carried out educational, public climate change presentations, one-on-one interviews, and a 24-question climate change sentiment survey in order to raise public awareness about climate change causes, impacts, and solutions across multiple states in the U.S. During the field campaign, we asked the following key questions, which are the focus of this study: (1) Does conventional climate outreach reach those who are skeptical about climate change as well as people of diverse social and economic backgrounds? (2) To what extent is public concern over climate change translating to political engagement on the issue? (3) Which climate impacts, if any, are being perceived by communities across the U.S.? (4) To what extent, and in what form, are climate-adaptation measures being employed in communities across the U.S.? (5) Does climate change sentiment differ between communities and age groups across the county? (6) What lessons and effective strategies, if any, can we learn through an in-the-field national outreach campaign that can improve future climate outreach and communication?

Based on community experiences and concerns that have emerged through prior and ongoing discussions with our community partners and affected residents, and review of the literature, we hypothesized that conventional climate outreach strategies are failing to reach those who are skeptical about climate change as well as youth communities and communities of color. We also hypothesized that public concern over climate change is not yet translating to widespread political engagement on the issue, that climate-adaptation measures being employed are limited and mostly take the form of easily achievable measures such as installing window air conditioning and seeking shelter from extreme weather, and that climate change sentiment differs between communities and age groups across the county.

\section{Materials and Methods}

From 15 June to 15 November 2018, we carried out a national climate outreach campaign across 36 states in the U.S., which consisted of (1) public presentations about climate change; (2) one-on-one interviews with farmers, scientists/park rangers, NGO workers, and the general public; and (3) the dissemination of a 24-question climate change sentiment questionnaire to 500 residents. The first and third items were carried out in each state, whereas the second item was only carried out in states where we were able to arrange interviews. In general, states included in this field project were those that offered geographic heterogeneity while also allowing for efficient vehicular transport (i.e., contiguous states). This analysis was not able to consider all 50 states due to limited time and resources. Both quantitative and qualitative methods were employed to analyze data in this study, the details of which are described subsequently.

To adhere to principles of ethics, we would like to note that all participants who attended public presentations were present on a voluntary basis, all questionnaires were voluntary, all questionnaires were completely anonymous and did not collect private information (e.g., name and home address), and that all one-on-one interviews were conducted only after receiving verbal consent by the participant in the presence of a witnessing co-investigator.

\subsection{Public Outreach}

We collaborated with local community groups to organize and host 35 public climate-related presentations across the country. Presentations were held at school campuses $(n=10)$, churches $(n=4)$, public libraries $(n=5)$, restaurant banquet rooms $(n=3)$, bookstores $(n=1)$, and other community spaces $(n=12)$ (i.e., nature centers and apartment commons). Community groups with whom we 
collaborated included the non-profit Citizens' Climate Lobby $(n=15)$, Sierra Club $(n=3)$, local churches $(n=3)$, nature conservancies $(n=3)$, colleges $(n=7)$ and other groups (i.e., coffee houses and other non-profits). These collaborations were typically established via email. About half of our college presentations were in-class presentations to science classes, while the other half were on-campus events organized by students. Presentations were advertised to the public, with the choice of advertising method left to the local community partner. Methods of advertising included posters and bulletins, the creation of Facebook events, list-serve email announcements, as well as occasional newspaper and radio announcements. The majority $(\sim 90 \%)$ of events were planned and advertised between four and eight weeks in advance. The flexibility of these methods of outreach and advertising mirrored the diverse array of approaches commonly practiced by community organizers in the field.

Events consisted of a 35- to 45-min oral PowerPoint presentation, covering basic climate science, impacts, and solutions, as well as a 20- to 30-min question and answer period to follow. For about $10 \mathrm{~min}$ prior to each presentation, members of the audience were first asked whether they had been noticing climate-related changes or impacts in their local area, and to raise their hands and share those personal observations with the group. This question was asked before rather than after each presentation to avoid introducing bias in participant responses that might have otherwise occurred due to influence by presentation material. Participant responses were recorded and categorized for a subset of 15 of these groups (termed "Obs. Groups"). Group responses were then normalized to produce response rates in the form of histograms by region, which are presented in the results (normalization involved dividing the number of groups that reported a given climate impact within a region by the number of groups surveyed within that region). The locations of these groups are shown in Figure 1. While the remaining features in Figure 1 denote locations where questionnaires were collected, these locations also reflect the locations where public presentations were given, with the exception of the sites shown in OR, WA, OK, and MN which represent online questionnaire locations, but no on-site presentation.

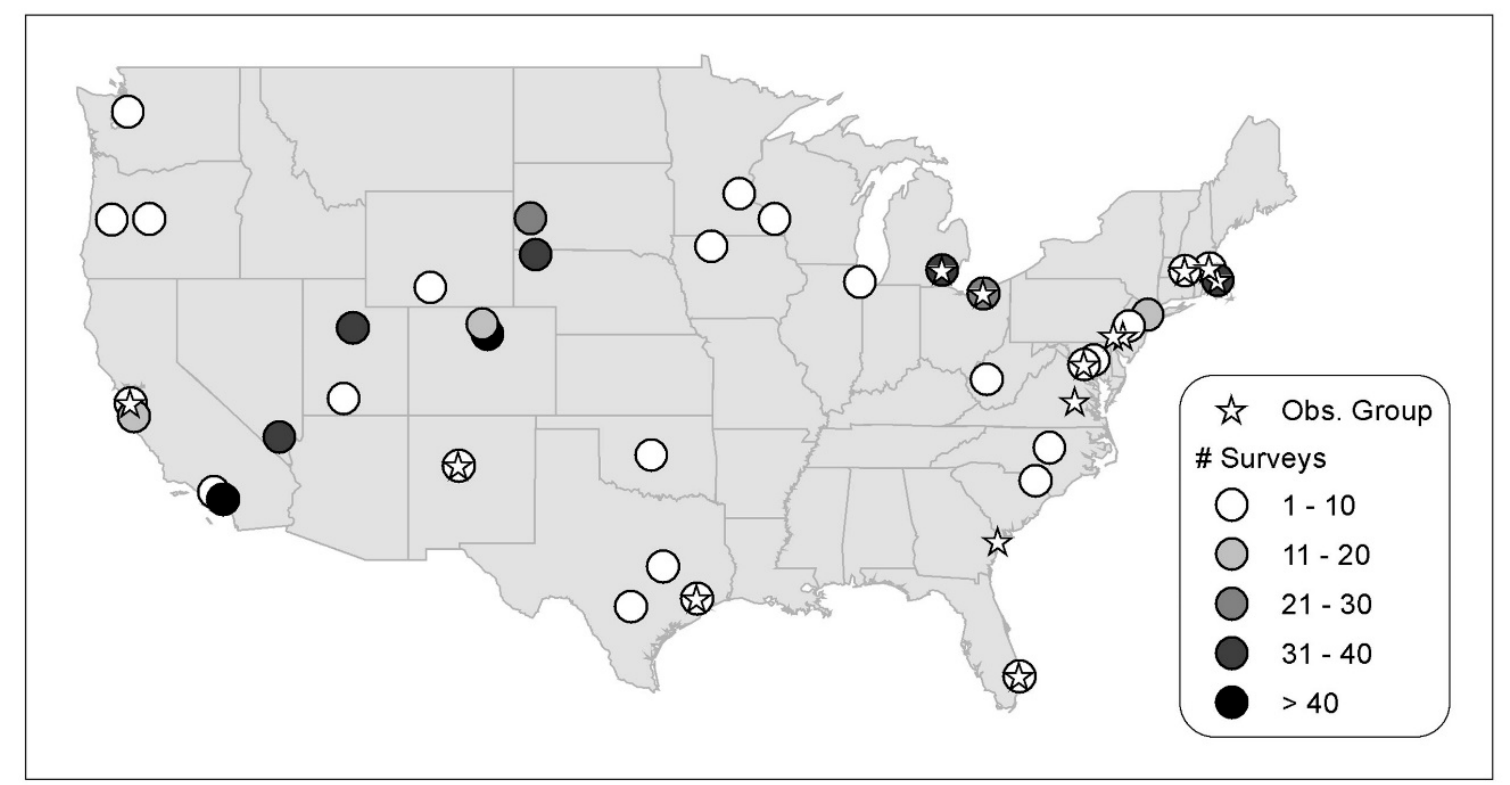

Figure 1. Locations and quantity of surveys collected in the U.S., along with the locations of 15 groups from whom climate-related observations were recorded. Note: "survey" sites also represent "presentation" sites, except in Oregon, Washington, and Oklahoma where online questionnaires were collected, but no on-site presentations took place.

Group responses were classified into 14 distinct categories in order to consolidate climate observations that were commonly reported by at least three groups. The only exception was for "more snowpack", which was an observation reported by only two groups but was still included as 
its own category since this was a counterintuitive observation that was less expected. Although the interpretation of most climate impact categories is straight forward (e.g., reduced snowpack, hotter temperatures, sea rise), there are two categories that require clarification. This includes "erratic weather" and "species impacts". In the former case, the category refers to reports of either dramatic intra-seasonal weather fluctuations (e.g., major diurnal or weekly temperature swings), unusual bouts of heavy rain punctuated by extended dry periods, or what some people referred to as "altered weather patterns" or "unpredictable weather". In the case of the species-related category, this refers to reports of either more new or invasive plant or animal species, fewer native species, or phenology mismatch (e.g., earlier spring causing flowers to bloom before bees are around to pollinate them). To determine the potential influence of group size on the number of impacts reported by groups, these two variables were plotted against one another and the Pearson correlation coefficient was calculated.

In addition to formal presentations, we carried out public-canvasing in the town centers of Cambridge, MA, and Boulder, $\mathrm{CO}$, in order to share educational climate information with the public and collect questionnaires. Though canvasing took place on a different day and month in each town, both locations saw a comparable amount of foot-traffic. During each canvasing effort, a 3-foot by 4-foot colored poster about climate change, accompanied by a layout of educational climate science books and flyers, was stationed at our site of outreach to inform people about climate change and our project. In Boulder, an active canvasing strategy was used, in which three volunteers approached people passing by and those sitting on nearby park benches in order to disseminate flyers and questionnaires. In Cambridge, a passive strategy was used in which a single individual stood by the banner, awaiting interaction by those passing by. Each canvasing effort took place over a one-hour period. Door-to-door canvasing in Tustin, CA, and Ann Arbor, MI, was also conducted in order to disseminate questionnaires to the greater public.

\subsection{Interviews}

One-on-one interviews with scientists (i.e., park rangers and university ecologists), farm owners, NGO workers, and the general public were conducted in order to learn more detailed information about various aspects of local climate impacts that cannot be readily obtained through questionnaires. These interviews also served as a form of qualitative validation when comparing responses to those reported during community gatherings. In each interview, individuals were asked to describe climate-related impacts or challenges being realized in their local communities, as well as any adaptation measures being employed or observed in their surrounding environments. There were 24 interviews carried out in total, involving seven scientists, seven NGO workers, four farmers, and six members of the general public. An approximately equal number of interviews were sourced from each region, including eight from the Southeast, six from the Southwest and Texas, five from the Northeast, and five from the Midwest.

With the exception of scientists, all individuals selected for interview were those with at least 25 years of residence in their state. In the case of scientists, only those with expertise in the ecology of the local area were interviewed. These selection criteria were applied to help ensure that individuals selected for interview were those who were capable of speaking to long term climatic changes over time, either through personal experience or science/research. Interviews were carried out using a semi-structured approach that consisted of several key questions intended to help define areas to be explored. Semi-structured interview methods have the benefit of allowing the interviewer or interviewee to diverge in order to pursue an idea or response in greater detail [30]. As noted by Steward et al. (2008), the flexibility of this approach, especially when compared to structured interviews, also allows for the discovery or elaboration of useful information that may not have previously occurred to the research team [31].

For data analysis, we employed a hybrid approach that borrowed from both deductive and inductive interview methods. That is, we analyzed interviews by applying a predetermined framework that allowed us to assess the existence of different known climate impacts. This deductive approach is 
useful in studies where researchers have knowledge of probable participant responses, [32], as was the case in our analysis given the extensive literature that exists documenting climate impacts around the world. However, we also allowed for the possibility of themes and climate impacts to emerge that were not initially anticipated, which we would then document and build into our framework when examining subsequent interviews. This inductive component, which uses the actual data themselves to inform the structure of the analysis is more time consuming; however, it is more comprehensive and allows for both greater flexibility of the analysis while reducing the potential for biasing the analysis framework [32]. Such methods have been used extensively in prior qualitative research, with a more exhaustive discussion of the tradeoffs presented elsewhere [32-35].

All interviews were video recorded for educational purposes. This also allowed for repeated revisiting of the interview material to confirm responses and ensure accurate logging of noteworthy comments. This approach is consistent with the recommendations for qualitative research outlined by Nobel and Smith (2015) [36]. As with Section 2.1, responses were classified into 14 distinct categories, normalized by geographic region, and presented as histograms to enable comparisons with responses by community gatherings.

\subsection{Questionnaire}

A 24-question climate change sentiment survey was developed and disseminated to communities across the U.S. in printed and online form. All questions were in check-box format, with no written answer sections. The questionnaire was administered using the following three approaches: (1) in-person dissemination to those who attended public climate presentations, (2) online dissemination to those who attended public climate presentations (or otherwise decided to visit our survey website), and (3) in-person dissemination and collection via door-to-door outreach and public canvasing.

For the first half of the outreach campaign, the first approach was used to collect surveys, while the second approach was used for the second half of the campaign. This allowed us to compare the two different data collection methods (the latter approach being less time- and resource-intensive). For the second approach, audience members were asked to complete an online questionnaire following the event and were provided with the survey website link to do so. The third approach was used to survey members of the general public at select locations during the first half of the campaign.

Questionnaires that we collected were divided into three different categories for analysis, depending on the type of outreach the survey participant was involved in and whether he/she attended one of our climate presentations. Questionnaires by participants who attended one of our presentations were considered part of the "Presentation Group", whereas those collected by door-to-door activities or street canvasing were referred to as the "General Public Group". Since the Presentation Group included some presentations to college classrooms, where attendance depended on prior enrollment and where the sample population was unique (college students), we also created a third group within the Presentation Group referred to as the "College Group". The locations where questionnaires were collected and the number of questionnaires collected at each location are shown in Figure 1.

\section{Results}

\subsection{Community Outreach}

Attendance to climate presentations ranged from 5 to 70 people, with an average attendance of approximately 22 people per event (standard deviation: $~ 17$ people). On average, the Presentation Group $(n=428)$ was $47 \%$ male and $53 \%$ female. Attendance was not heterogenous in terms of race/ethnicity, age, and education. The overwhelming majority of attendees were Caucasian $(84.1 \%)$, between ages 45 and 65 (66.7\%), with at least an undergraduate or professional degree $(77.8 \%)$.

Figure 2 presents results from a subset of 15 communities (Obs. Groups) within the Presentation Group who were invited to share (prior to each presentation) climate-related changes they had observed 
in their local areas over time. Among the 15 communities, six were from the Northeast, four from the Southwest and Texas, three from the Southeast, and two from the Midwest. The graph shows the percent of community groups in which a given observation was voiced by at least one community member. Responses are normalized by region, and also normalized for all regions combined. Although responses varied by region, the most frequently cited climate observation (by $\sim 70 \%$ of groups) across all regions was hotter temperatures, followed closely by species impacts (new plant and animal species, or a difference in the prevalence of existing species) and increased flooding. Regarding species, observations often related to insects (e.g., more ticks and fewer butterflies). Regarding temperature, over a third of communities reported "hotter nighttime temperatures". Higher snowpack was reported by one community in the Northeast, compared to the opposite observation reported by three communities. Observations of sea level rise and/or coastal erosion were mostly reported by communities in the Northeast and Southeast.

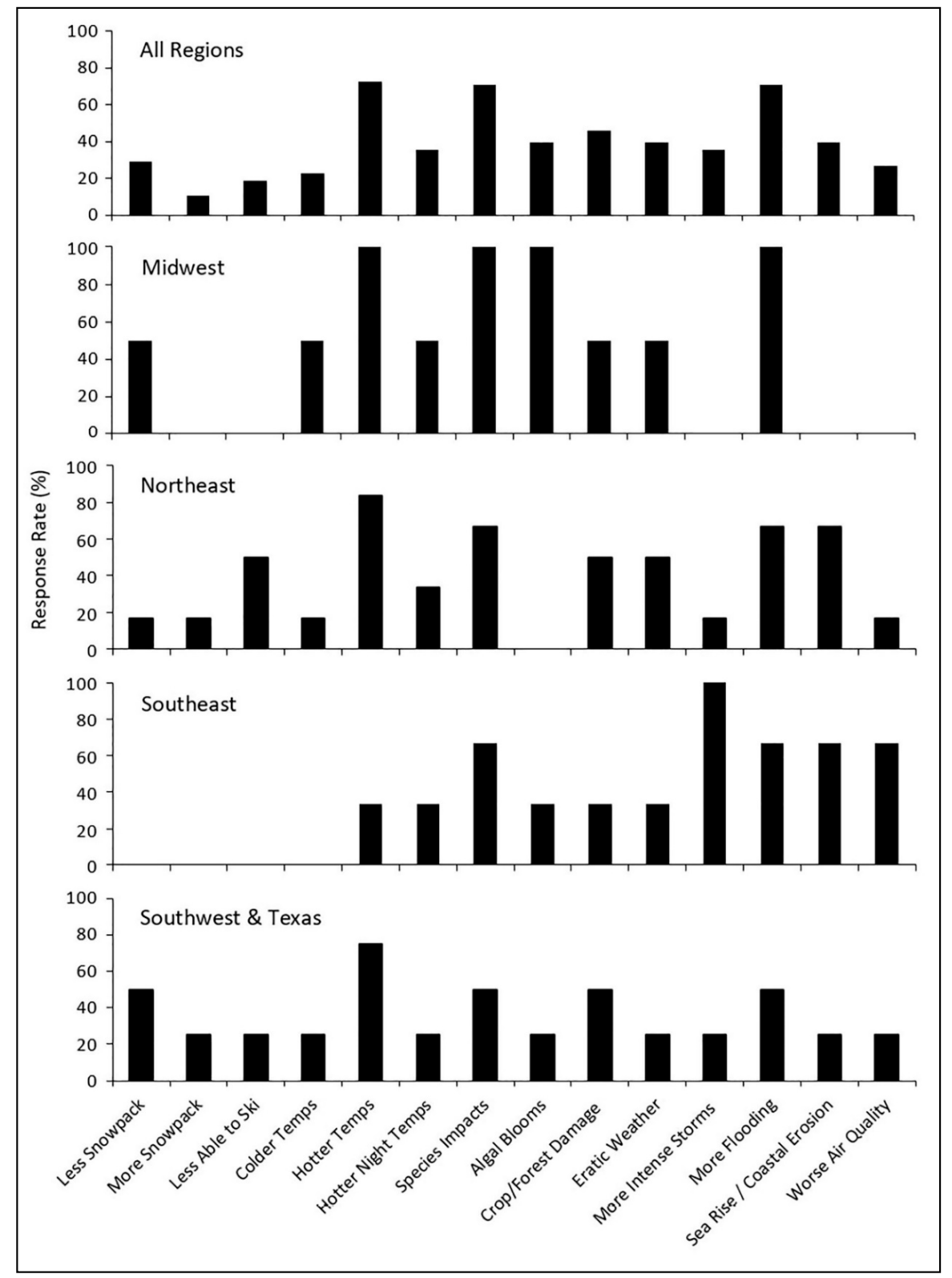

Figure 2. Local climate-related impacts observed by community members of 15 groups across the U.S. 
When examining reported observations by region, hotter temperatures, more flooding, sea rise/coastal erosion, and species impacts were the most frequently reported climate-related observations by communities in the Northeast. Compared to other groups, these communities were also the most frequent to report reduced wintertime recreation (e.g., skiing). In the Southeast, the most frequently reported observation was more intense storms, whereas "hotter temperatures" was the most frequently reported observation in the Southwest and Texas. Although hotter temperatures, species impacts, algal blooms, and more flooding were equally reported as the most frequent observations in the Midwest, the percent response rates should be interpreted with caution for this region given that only two communities were sampled. Importantly, while group sizes varied, Figure S1 (in Supplemental Section) demonstrates that the number of climate impacts reported by groups was not correlated with group size $(r=-0.22)$.

Climate-related changes (and regions) that were reported by fewer than three groups, and therefore, not included in Figure 2, included drought and wildfire (Southwest and Texas); milder winters (Southwest and Texas, and Midwest); as well as energy costs, insurance costs, infectious disease, warmer ocean waters, and property damage (Southwest and Texas, and Northeast).

\subsection{Interviews}

Climate impacts reported through one-on-one interviews for each region are presented in Figure S2 of the Supplemental Section. Results tended to be similar to those reported by community groups across the U.S., which reinforces the reliability of participant responses. Interviews typically ran between 30 and $40 \mathrm{~min}$ in length, totaling to approximately $14 \mathrm{~h}$ of interview time.

Results from two one-on-one interviews with environmental justice groups affirmed the results presented in Figure 2, but also highlighted climate impacts that are disproportionately affecting low-income communities and communities of color. These include heat-related mortality among people living in public housing where air conditioning is limited or does not exist, the gentrification of high-elevation coastal regions that is forcing such people to move to low-lying areas vulnerable to sea level rise, and the disproportionate heating/cooling bills and structural home damage suffered by those living in poorly insulated or structurally weak housing (e.g., mobile homes) as a result of extreme temperatures and weather events. In a low-income Native American community where structurally weak trailer homes are prevalent, an increase in the frequency of large-sized hail events has resulted in a disproportionate vulnerability to storm-related property damage, according to one resident.

Results in Figure 2 were also affirmed by interviews with farmers. In one case, a farmer in South Dakota described rainfall as more concentrated and sporadic, describing the presence of heavy downpours for several days accompanied by two- to three-week periods of little or no rain in between. Such irregularities are particularly problematic since many farms in the region are not irrigated, but instead rely on regular and predictable rainfall. A farmer in Minnesota echoed similar concerns, describing a recent precipitation event in which 17 inches of rain fell in a single 24-h period, resulting in widespread soil erosion and crop loss.

In Massachusetts, an apple/peach farmer described recent decades as being exceptionally difficult for crops due to irregular patterns in spring weather and "cold snaps" in winter. While peaches are a cold-adapted species, she explained that wintertime temperatures in the prior year were so low that even the dormant peach buds did not survive. Consequently, the orchard did not blossom to produce peaches in the spring. She also described early spring warming events that trigger premature blossoms which become destroyed as frigid wintertime conditions resume. In other instances, unusually rapid spring warming is creating biological water demand before underground irrigation pipes have thawed, leading to crop stress.

As it relates to species impacts, a common theme that was echoed across multiple interviews was the notion of phenology mismatch. In some cases, this meant the early or delayed onset of seasons, causing insects and flowers to be out of sync (impacting insect survival and pollination), as well as birds and their insect/flower foods. Similarly, in the Colorado Rocky Mountains, white-fur-colored mammals 
which were previously camouflaged against the white snow are reportedly becoming vulnerable to increased predation as earlier snowmelt exposes the relatively dark under-terrain before the animals' fur coats have had time to change. In this same region, a park ranger explained that bark beetles, while native to the area, have reached "epidemic levels" due to progressively warmer wintertime temperatures, which has led to widespread pine tree mortality. In Florida, warming temperatures appeared to be playing a negative role in combating warm-adapted invasive species such as apple snails and iguanas. According to one biologist in the region, "fewer cold spells" have resulted in an "explosion in iguana populations".

When asked whether they were applying any climate-related adaptation measures, two of four farmers replied in the affirmative. To contend with extreme precipitation events in Minnesota and minimize soil erosion, one farm owner had begun planting cover crops, while in the Northeast one farm owner had begun using more pesticides to contend with what the farmer described as "new pests making their way into New England", along with fungus.

When the same question was asked to individuals working for NGOs, three of seven replied in the affirmative, describing measures that ranged from free climate leadership programs on climate resiliency and emergency preparedness to innovative design towards green infrastructure. In South Dakota, where we encountered first-hand reports of a trend towards increasing major storm activity, one Native American NGO leader described a large effort underway to construct climate-resilient homes that can withstand 120 mile per hour $(\sim 190 \mathrm{~km} / \mathrm{hr})$ consistent wind speeds as well as collect rainwater for reuse. The community has also developed local farming practices to ensure greater food security.

When interviewing local park rangers and ecologists about adaptation measures, four described measures that were already underway, such as the controlling of invasive species and the protection of vulnerable animal species to restore natural resiliency in the environment, as well as the removal of dead pine trees (killed mostly by drought and bark beetle damage) to reduce wildfire risk. In one case, there was a pilot project underway in a saltwater marsh in southern California to combat sea level rise through the deposition of sand intended to raise the level of the marshland habitat. Despite these efforts, some individuals described the need for major efforts that were not yet underway due to political and economic obstacles. Such projects included the rebuilding of natural ecosystem resiliency through the removal of manmade barriers to historic freshwater flow, which would help combat saltwater intrusion and return seashore sediment to help combat sea level rise. In one case in the Northeast, natural resiliency of a marsh area was described as a recent major storm deposited ten years of sediment onto the marsh in just two days.

In general, approximately $40 \%$ to $60 \%$ of farmers, NGO workers, and park rangers/ecologists, when asked, could describe climate adaptation measures already underway in their homes or communities. With the exception of some residents who described using more air conditioning, the group comprised of the general public mostly described solutions to help avoid climate change as opposed to measures to adapt to and/or cope with climate change. In two interviews conducted in regions recently hit by major hurricanes (Texas and Florida), residents expressed future plans to move out of their towns into lower risk areas.

\subsection{Questionnaire}

During the field campaign, a total of 500 questionnaires were collected. Of these, $428(85.6 \%)$ consisted of the Presentation Group (344 filled out by hand and 83 online) and 72 (14.4\%) consisted of the General Public group (filled out by hand). Within the Presentation Group, a subset of 68 consisted of the College Group. For the Presentation Group, written questionnaires that were passed out to audience members yielded a high response rate ( $>90 \%)$ across 17 groups (first half of field campaign), compared to online questionnaires which yielded a much lower response rate $(<12 \%)$ across 18 groups (second half of field campaign). As it relates to the general public, both an active and passive approach were used to collect questionnaires. The active approach led to the collection of 14 questionnaires and 
over a dozen points of public engagement (e.g., conversations about climate change), compared to zero questionnaires collected via the passive approach and only two points of public engagement. Characteristics of the entire sample population are presented in Table 1.

Table 1. Characteristics of survey participants.

\begin{tabular}{lrllrl}
\hline Race/Ethnicity & & & Gender & & \\
\hline Caucasian & $77.4 \%$ & $n=380$ & Male & $43.1 \%$ & $n=170$ \\
African American & $2.4 \%$ & $n=12$ & Female & $56.9 \%$ & $n=224$ \\
Hispanic & $6.9 \%$ & $n=34$ & & & \\
Native American & $0.8 \%$ & $n=4$ & State & & \\
\cline { 2 - 6 } Arab & $0.4 \%$ & $n=2$ & CA & $23.4 \%$ & $n=115$ \\
Asian & $7.9 \%$ & $n=39$ & CO & $13.8 \%$ & $n=68$ \\
Other & $4.1 \%$ & $n=20$ & MA & $9.1 \%$ & $n=45$ \\
& & & UT & $8.3 \%$ & $n=41$ \\
Age & & & NV & $7.9 \%$ & $n=39$ \\
\hline$<18$ & $1.8 \%$ & $n=9$ & NE & $7.7 \%$ & $n=38$ \\
$18-30$ & $29.5 \%$ & $n=145$ & MI & $6.9 \%$ & $n=34$ \\
$30-45$ & $12.0 \%$ & $n=59$ & SD & $5.8 \%$ & $n=29$ \\
$45-65$ & $25.0 \%$ & $n=123$ & OH & $4.5 \%$ & $n=22$ \\
65+ & $31.5 \%$ & $n=155$ & NY & $3.3 \%$ & $n=16$ \\
& & & a Other & $9.3 \%$ & $n=53$ \\
Education & & & & & \\
\hline None & $1.4 \%$ & $n=7$ & & & \\
High School & $4.7 \%$ & $n=23$ & & & \\
Some College & $25.2 \%$ & $n=123$ & & & \\
Completed College & $31.5 \%$ & $n=157$ & & & \\
Professional & $5.1 \%$ & $n=25$ & & & \\
Degree & $31.5 \%$ & $n=154$ & & & \\
Masters/PhD & & & & \\
\hline
\end{tabular}

Note: Categories do not necessarily add up to 500 (total surveys collected) since online surveys did not collect gender data, and because some surveys had missing data. ${ }^{a}$ Refers to CT, DC, FL, HI, IA, IL, MD, MN, MO, NC, NH, NM, NY, OK, OR, PA, SC, TN, TX, WA, WV, WY.

Since the Presentation Group accounted for most of the sample population, characteristics presented in Table 1 are virtually the same between the Presentation Group and the larger sample population. Compared to the sample population as a whole, the General Public group was also nearly the same in terms of demographics. However, the proportion of Caucasians was slightly higher $(81.7 \%)$, and the age distribution was more evenly distributed with approximately $25 \% \pm 3 \%$ of respondents falling into each age category (except for the youngest category: $2.8 \%$ ), compared to the bimodal distribution of the Presentation Group (relatively fewer middle-aged people).

In terms of political affiliation, the Presentation Group mostly identified as Democrats (65.1\%), compared to $8.5 \%$ Republicans, and $26.4 \%$ who identified as Independents or "other". Results were nearly the same $( \pm 4 \%)$ across each political category for the General Public Group as well as the College Group.

\subsubsection{Climate Awareness}

Survey responses among the Presentation Group were quite homogenous across a variety of questions. The overwhelming majority of individuals who attended presentations about climate change were those who already "believe the climate is changing" (98.5\%) and "strongly agree" that "humans are the main cause of climate change" (85.8\%). Responses differed only slightly among the General Public Group, with $90.3 \%$ and $81.9 \%$ reporting these same answers, respectively. Approximately $7 \%$ of the General Public Group reported being "unsure" about whether the climate is changing. 
Over the entire sample population, less than $2 \%(n=10)$ either "strongly" or "somewhat" disagreed that climate change is anthropogenic. Among the General Public Group, this proportion was higher (5.6\%). Among the General Public Group, 4 of 7 Republicans (57.1\%) reported to either "strongly" or "somewhat" disagree that climate change is anthropogenic, compared to only 3 of 41 Democrats $(7.1 \%)$. Two-thirds of those who refuted anthropogenic climate change did not refute that the climate is nonetheless changing.

\subsubsection{Climate Concern}

When asked to rank the issue of climate change in terms of priorities $(1=$ highest priority, $10=$ lowest priority), $34.0 \%$ of the Presentation Group ranked climate change as their highest priority, compared to $26.6 \%$ of the General Public Group, and $21.2 \%$ of the College Group. Nearly two-thirds $(61.5 \%)$ of the Presentation Group ranked climate change among their top three priorities, compared to $62.5 \%$ of the General Public Group and only $39.5 \%$ of the College Group.

When participants across the entire sample population were asked to rank their top three climate-related concerns (from a list of 14 possible impacts identified through prior research), the choice that was most frequently cited as the number one concern was "future generations", followed by "water supply" and "species/habitat loss" (Figure 3). The choice that was most frequently cited among people's top three concerns was "water supply". National security, property value, infectious disease, and the economy were least frequently ranked among people's top three concerns.

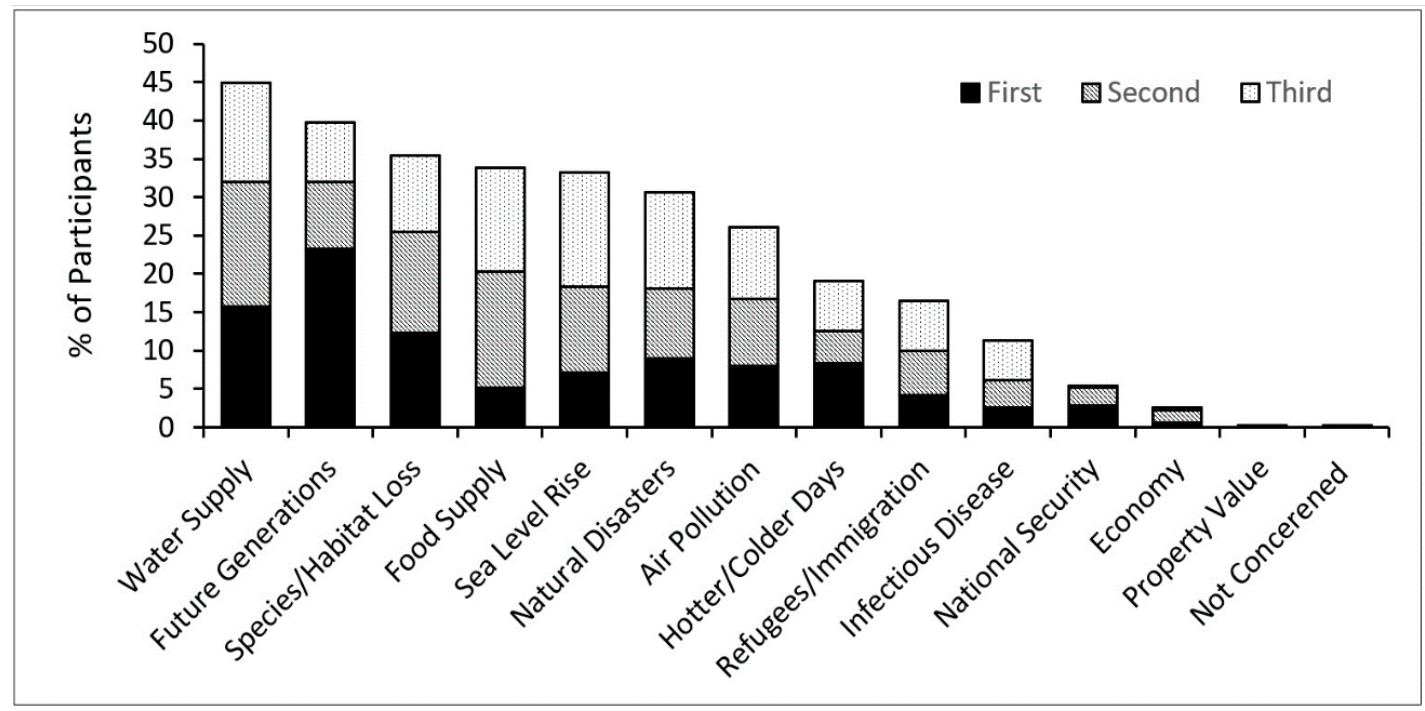

Figure 3. The proportion of the sample population who ranked an issue as their first, second, or third highest climate-related concern.

Of note, Figure 3 represents a smaller sample size $(n=310)$ compared to the entire sample population since some participants did not numerically rank their concerns. However, when we observed the climate concerns that were among people's top five concerns regardless of rank, allowing us to increase our sample size $(n=447)$, the relative magnitude of each climate concern in Figure 3 did not change.

Of survey participants aged 30 and under who assigned a numerical rank to their top climate-related concerns $(n=91)$, the pattern of results was similar to Figure 1. "Future generations" and "species/habitat loss" were the most frequently cited number one concerns, each cited by $20 \%$ of the population, followed closely by "water supply". Most frequently cited among the top three concerns was "water supply". Despite the young age of this group, approximately one-third reported "future generations" among their top three climate-related concerns. As with the larger sample population, national security, property value, infectious disease, and the economy were infrequently ranked as top climate-related concerns. 
Among the Presentation Group, 13.2\% reported either "rarely" or "never" having conversations about climate change. This was largely driven by college students, $26 \%$ of whom responded this way. The feeling of being "hopeless" about climate change was reported most frequently among the General Public Group (25.4\%), compared to the Presentation Group (15.5\%). Among the latter group, hopelessness was mostly reported by college students (22.5\%). However, college students also most frequently reported being "hopeful" (37.3\%). The majority of people (48-56\%) across both the Presentation Group and General Public Group reported that their mood "varies", with zero people reporting that they "don't care".

\subsubsection{Climate Impacts}

When asking if climate change and human health are connected, the majority ( $>91 \%)$ across all groups replied in the affirmative, with approximately $85 \%$ reporting that they expect climate change to increase mortality in the U.S. When asked specifics, the vast majority $(>73 \%)$ in both the Presentation Group and General Public Group reported that they expect climate change to "negatively affect 75-100\% of the U.S. population", with 10-14\% reporting that only "50-75\%" of the population will be affected. Among the former group, the proportion of college students who expect "75-100\%" of people to be affected was notably lower $(62.5 \%)$, with about twice as high a proportion $(25.0 \%)$ reporting that only "50-75\%" of the population will be affected. Very few people across all groups (11-15\%) believed that only $50 \%$ or less of the population will be affected by climate change, with the General Public Group accounting for the higher end of the range.

\subsubsection{Climate Action}

When asked "Should the U.S. spend money to help low-income countries reduce their carbon emissions?", most people among both the Presentation Group and General Public Group replied in the affirmative ( $72 \%-77 \%)$, with approximately $14 \%-19 \%$ reporting to be "unsure". When asked "Is your local government doing anything to address climate change?", an approximately equal proportion of people in the Presentation Group replied in the affirmative as those who replied "unsure" $(\sim 40 \%)$. For the General Public Group, slightly more people (46.0\%) felt their local government was addressing climate change. The College Group reported being "unsure" at a much higher frequency $(75.4 \%)$. Over $90 \%$ of the General Public Group and Presentation Group reported to be "willing to pay a small tax to help reduce carbon emissions and boost green business". The percentage was slightly lower for the College Group (83.6\%).

When asked how important climate policy was in deciding who to vote for in the upcoming (now past) midterm congressional elections, $72.0 \%$ of the General Public Group responded "very" important, compared to $79.3 \%$ of the Presentation Group, and $63.0 \%$ of the College Group.

When the General Public Group was asked if they had "ever" contacted a local politician to voice their opinion about "any issue", and about "climate change", an approximately equal proportion $(\sim 33 \%)$ reported "yes, often", "yes, rarely", and "no" (relating to "any issue"). These proportions were similar for the Presentation Group, with an increase in those reporting "yes, often" $(44.2 \%)$. The College Group reported to be less engaged, with $77.4 \%$ stating they had not ever contacted their local politicians about any issue.

On the issue of climate change, the proportion of those having contacted their local politicians dropped substantially, with over half of the General Public Group (51.1\%) and Presentation Group $(53.3 \%)$ reporting that they had not ever contacted a local politician about climate change. For the latter group, the higher percentage was driven largely by college students, $82.0 \%$ of whom reported this response. When we excluded college classroom presentations from the average, the frequency of this response was still high (50.3\%) among the Presentation Group. While civic engagement was modest across the General Public Group and Presentation Group, a much higher proportion ( $80 \%)$ reported being "aware of policies or other solutions to address climate change". By contrast, only $60.0 \%$ of the College Group was aware of such solutions. 
Regarding community engagement on climate change, $67.2 \%$ of the General Public Group reported to "sometimes" or "often" volunteer for (any) community groups, compared to a higher proportion $(87.9 \%)$ who reported a willingness to volunteer for a local climate action group if they knew about one. This same trend was observed among the Presentation Group, at proportions of $82.5 \%$ and $90.8 \%$, respectively. Among this group, the difference was most pronounced among college students, with $56.4 \%$ reporting to currently volunteer and $80.3 \%$ reporting a willingness to volunteer.

When participants across the entire sample population ranked their top three sources of news (from a list of six possible options), the choices most frequently cited were online sources $(>50 \%)$. In the College Group, a relatively higher proportion identified the internet as a primary source, and a substantially lower proportion identified newspapers as a primary source (Figure 4). Facebook alone was ranked above the newspaper as a primary news source among the College Group, while the television was reported approximately equally across subgroups $(\sim 50 \%)$.

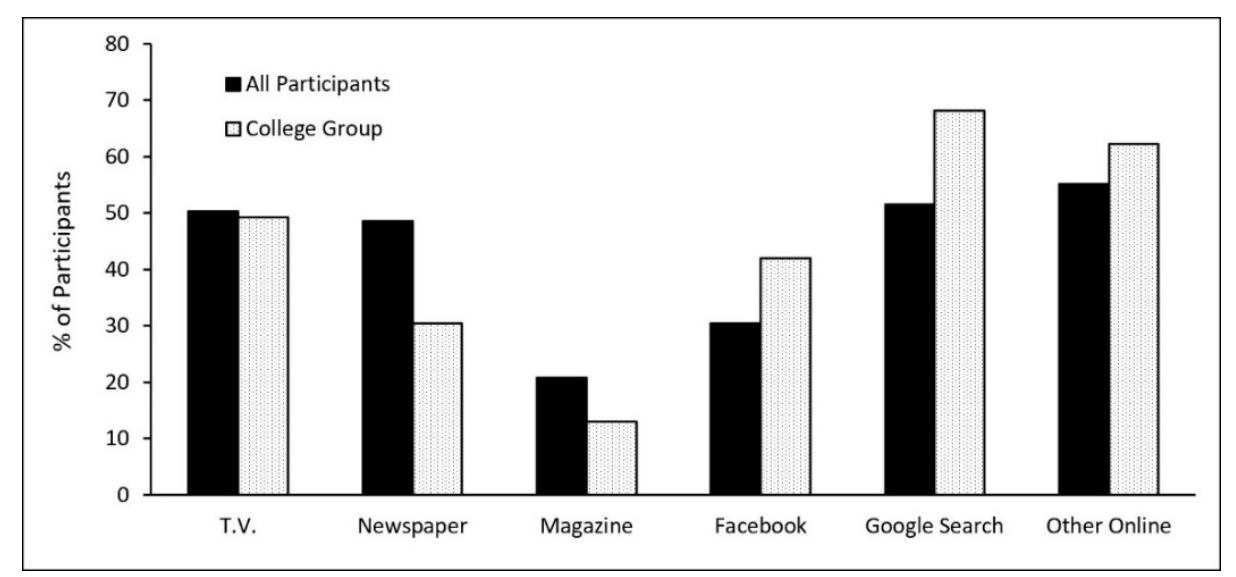

Figure 4. Proportion of those ranking a given news sources among their top-three sources of news.

\section{Discussion}

Results from a national climate outreach campaign were examined separately for three different sample populations. This analysis generally found that the greatest attendance to our climate change events was college educated Caucasians who identified as Democrats, and that important knowledge gaps existed among this group, underscoring the need for further public outreach.

\subsection{Community Outreach}

Among a subset of 15 groups who attended climate presentations across the U.S., in-person conversations and interviews demonstrated a variety of climate-related changes that communities are noticing at a local level. Hotter temperatures, increased flooding, and species impacts (changes in species prevalence) were the most commonly reported impacts, with crop/forest damage, erratic weather, and algal blooms being less, but still commonly, reported. As it relates to temperature, reports by community members described conditions in which students are sometimes not allowed to play outside due to excessive heat. In schools without air conditioning, "early dismissal days" occur as a result. The fact that heat is the primary cause of weather-related mortality in the U.S. underscores the seriousness of excessive heat [37]. Hotter wintertime temperatures were also reported by communities we visited, with elderly community members in the Northeast describing recent winters that "no longer allow outdoor ice skating". Higher nighttime temperatures were also reported across five groups. Reported climate impacts by community groups and one-on-one interviews tended to show approximate agreement across regions, in turn reinforcing the reliability of participant responses. These findings highlight areas warranting the attention of city planners and policymakers as they relate to climate adaptation strategies. 
Those who attended our public presentations tended to be older, highly educated, and Caucasian. This could be due to a variety of factors. A 2014 report on the state of diversity in environmental organizations generally showed very low involvement among minority groups in mainstream environment organizations in the U.S. [38]. Since we partnered with these organizations in the planning of our events, it is possible that minority groups were less aware of our events (e.g., not on the mailing list of the organization).

A deeper question as to why involvement in such organizations differs across ethnic groups, however, is also important to answer. This may have to do with an anecdote that we encountered from a Native American community leader with whom we spoke. When asked about a possible collaboration to host an educational climate outreach event, he stated that Native Americans are facing climate change as it is commonly understood, as well as "climate change" within the household, referring to unemployment, poverty, alcoholism, and other stressors that are disproportionately affecting minority groups. In brief, minority and low-income groups may be less involved in environmental organizations because these communities are facing more urgent short-term problems. Research also suggests the influence of other factors that limit involvement, such as cost-prohibitive membership and inability to take unpaid internships [38]. Regardless of the underlying reason, the lack of demographic heterogeneity among attendees to our presentations underscores the importance of targeted efforts to reach diverse communities, beyond simply partnering up with major environmental organizations. This could include partnering with smaller community organizations, particularly those focused on issues of environmental justice, as well as collaborating with school districts in low-income communities and communities of color. To engage such communities, environmental justice leaders highlight the importance of reframing the climate problem to focus more on the ways climate change affects communities, is immersed in social justice, affects public health, and is interwoven with issues of air pollution, transportation, and industrial facilities, as opposed to focusing on polar bears, wildlife, and "abstractions like parts per million" [15]. The importance of engaging diverse communities is reinforced by the higher percentage of African Americans, Latinos, and Asian Americans who regard global warming as "extremely" or "very" serious relative to Whites, according to national polling $[6,39,40]$, as well as the high fraction of the U.S. population that such communities account for.

The majority of those who attended our climate presentations already believe the climate is changing, and that human activity is the main cause. This is not surprising given that attendance to public presentations was voluntary, thus enabling a selection bias. Understanding the perspectives of those who attend public climate change presentations is nonetheless useful in enabling climate communicators to tailor educational information accordingly. In the case of this analysis, the makeup of audience members suggests that information aimed at convincing people of the existence of climate change and its anthropogenic nature is not necessary. Instead, explanations about climate solutions may be more useful.

While our educational campaign did not reach many of those who are dismissive about climate change, recent polling suggests that such individuals represent less than $10 \%$ of the U.S. population and that these individuals are already resolute about their opinion [5]. Thus, a climate change presentation to this group would likely be more difficult to construct and require more resources in order to recruit participants. It is also likely that a climate presentation to such participants would be less likely to lead to behavioral change, compared to groups who are open to learning about and/or are already interested in climate solutions, since individuals who are dismissive of climate change are considered to be "very sure it is not happening and are actively involved as opponents of a national effort to reduce greenhouse gas emissions", according to national polling at Yale University [5].

\subsection{Interviews and Questionnaire}

One-on-one interviews revealed many anecdotes relating to climatic impacts to agriculture, including extended dry periods followed by extreme precipitation events, as well as climate impacts that are disproportionately affecting low-income communities and communities of color, such as 
heat-related mortality, elevated heating and cooling costs, gentrification, and extreme storm events. These findings are consistent with prior literature that has demonstrated disproportionate social vulnerabilities and impacts suffered by low-income communities and communities of color in the wake of Hurricane Katrina [41] and Hurricane Harvey [42], as well as broader work examining the so-called "Climate Gap" that renders such communities disproportionately vulnerable to extreme weather events, unemployment, the costs of basic necessities (i.e., water, energy and food), and other factors related to climate change [43]. In aggregate, these findings underscore the necessity of allocating local, state, and/or federal funds, along with other resources, to ensure the protection of low-income, vulnerable communities, and agricultural workers who are at an elevated risk of climate-related impacts. In reviewing the growing body of research on the intersection of climate change and environmental justice, Shonkoff et al. (2010) concludes that in the absence of proactive policies to address equity concerns, climate change is likely to amplify current and future socioeconomic disparities, leaving minority, low-income, and politically marginalized groups with fewer economic opportunities and greater environmental and health burdens [43].

In terms of adaptation, one-on-one interviews suggested that a variety of adaptation measures are being employed in communities and homes; however, such measures were mostly prevalent and familiar among farmers, ecologists, and NGO workers, as opposed to those we interviewed from the general public. Natural ecosystem adaptation was rarely mentioned, except for one case in the Northeast where increased sediment deposition was observed following a major storm, suggesting that some ecosystems may possess an element of unexpected resilience as it relates to climate impacts. These findings underscore the importance of outreach and education to empower the general public to prepare for and adapt to climate change.

In terms of questionnaires, participants who were asked to rank their top climate-related concerns most often cited concern for "future generations". This suggests that even among groups who have a better-than-average understanding and/or interest for climate change, the issue is still mostly perceived as a future problem. Concern for future generations was a top concern even among younger individuals, further suggesting the perception of climate change as a distant threat. The notion of climate change being a future problem runs counter to the recent National Climate Assessment and other reports, in addition to our own one-on-one interviews with community members, which document major climate-related impacts already underway [2,37]. Such impacts, including increased severe weather and wildfires, cost the U.S. over USD 300 billion in 2017 alone [44].

"Water supply" was most frequently ranked among people's top three climate-related concerns, which is consistent with a recent international poll that found "drought or water shortages" to be the most commonly reported climate-related concern in the U.S. as well as five other major regions of the world [7].

Climate-related concerns that were reported least frequently included concerns about the economy, property value, and national security. Given that citizens typically care about these issues, it was interesting to find that they did not rank among people's top climate-related concerns. This may suggest an important disconnect as it relates to the public's perception of climate change as an economic and security threat. Importantly, this perception runs counter to climate-related impacts and projections in the literature. Experts project the loss of two billion labor hours annually and an estimated USD 160 billion in lost wages by 2090 in the U.S. under a higher warming scenario [2]. Additionally, climate change undermines global political stability, leading to increased refugees, and threatens U.S. military infrastructure around the world [45].

The United Nations Refugee Agency reports that already over 20 million people have been forcibly displaced by climate-related natural disasters each year since 2008, with numbers projected to increase markedly by 2050 [46]. Additionally, climate impacts such as sea level rise and increases in extreme weather are expected to threaten U.S. military bases domestically and overseas, as well as contribute to poverty, environmental degradation, food insecurity, and political instability, which are conditions that breed terrorist activity [47]. The U.S. Defense Secretary Chuck Hagel called climate change a "threat 
multiplier . . . because it has the potential to exacerbate many of the challenges we already confront today-from infectious disease to armed insurgencies" [48].

Although climate change has led to the increased prevalence and expansion of disease vectors such as ticks and mosquitos [49,50], infectious disease was infrequently ranked among people's top climate-related concerns in our survey. In the wake of the 2016 Zika virus epidemic that created a national scare, it is reasonable to conclude that the low ranking of infectious disease as a climate-related concern is not because people are not concerned about infectious disease, but because they are again unaware of its connection with climate change.

The lack of a connection that individuals make between climate change and issues of the economy, national security, and infectious disease underscores an important knowledge gap that deserves considerable attention by climate communicators. Aside from general knowledge, evidence suggests that there may be an added benefit to raising awareness about these issues in the context of climate change. A study by Myers et al. (2012) found that reframing climate change in the context of public health and national security more readily elicits emotional reactions consistent with support for climate change mitigation and adaptation [14]. Furthermore, research on cognitive bias described by Zaval and Cornwell (2016) highlights how changing even a single word in a presentation can significantly influence perceptions of climate change and related policy, with conservative groups tending to respond more positively to climate mitigation when framed as a personal health risk as opposed to environmental risk [51]. An expanded discussion of the literature relating to the importance of climate-related framing can be found elsewhere [52].

Climate impacts that were observed by communities were not necessarily the same as those that were of greatest "concern" to communities. This may help explain the lack of public mobilization around climate solutions. That is, communities may not be focused on climate action because they have yet to see their greatest concerns become realized. Alternatively, this could reflect a greater fear of climate impacts that are less familiar.

Over half of the Presentation Group and General Public Group ranked climate change among their top three priorities. By comparison, $20 \%$ fewer college students ranked climate change among their top three priorities. The reduced perception of climate change as a priority among college students may be due to a higher number of other stressors facing college students, such as exams, school loans, job applications, etc. Alternatively, it may be a product of their age and reflect a lack of awareness about the impacts and severity of climate change, as well as an absence of first-hand experience in observing climate-related changes or impacts over time. The latter explanation is supported by research that has shown first-hand climate-related events (i.e., flooding) to be associated with people's perceptions about climate change [53]. Since the College Group in our analysis consisted mostly of science students, it is likely that our results here even overestimate the prioritization of climate change among the college demographic.

College students also reported feeling "hopeful" about climate change at a much higher frequency compared to other groups, despite reporting a much lower frequency of civic engagement on the issue. Taken together, these findings may suggest a more prevalent belief among college students that "someone else" is already addressing the issue, despite evidence of a mounting crisis [2]. Prior research has shown that younger people are indeed more likely than older people to believe the future will be better than the present [54]. Coupled with college students reporting high willingness to volunteer for climate-related community groups if they knew about one, and lower reported awareness of climate solutions, our findings underscore the importance of increased climate communication and education to inform college students about climate impacts and solutions.

While it is reasonable to characterize most of our Presentation Group as "climate-concerned", more than half of this group reported that they had not "ever" contacted a local politician about climate change. This suggests that that there is substantial room for increased civic engagement on the issue of climate change, even among concerned citizens. This underscores the importance of climate communicators and future outreach campaigns to encourage people to engage civically and develop 
relationships with elected officials about issues of climate change. Furthermore, this reinforces the notion that outreach efforts focused on filling knowledge gaps and mobilizing action among climate concerned individuals, as opposed to climate skeptics, is a worthwhile use of resources.

That a paucity of public pressure exists to influence climate policy was echoed in an in-person interview we carried out with Senator Elizabeth Warren's Legislative Correspondent in Washington D.C. When asked about the prospects of a federal tax being placed on greenhouse gas emissions, we were told that the Senator's office has yet to receive the public pressure (i.e., phone calls and letters) needed to place climate policy above other key issues on the political agenda.

The absence of sufficient public pressure to influence policy should not be taken to mean an absence of public support. In assessing public sentiment about climate change and policy, Leiserowitz and Akerlof (2010) showed that even during a serious economic recession with high unemployment, the majority of Americans supported a multitude of climate change and energy policies [55]. Hispanics and African Americans were often the greatest supporters of such policies, even when informed that individual costs would be incurred. Thus, translating existing public support into public pressure, or action, to bring about policy remains a critical next step. This point should not detract from the importance of continued efforts to build support for climate policy. Research by Fesenfeld and Rinscheid (2020) points to the complexity of garnering public support for climate policy, suggesting that perceived urgency is important, but that support depends largely on how policies are framed in terms of costs to the public [56]. Other research suggests that local as opposed to global framing of climate impacts increases support for the adoption of subnational climate policies [57].

In terms of political affiliation, the majority of those who attended climate presentations tended to identify as Democrats, compared to half as many Republicans. This finding agrees with prior polling that suggests that Democrats are more concerned about climate change compared to Republicans [16]. Among the General Public Group in our analysis, over 50\% of Republicans reported to either "strongly" or "somewhat" disagree that climate change is anthropogenic, compared to less than $10 \%$ of Democrats. Overall, the proportion of those in the General Public Group who refuted anthropogenic climate change equated to about $6 \%$. While these results must be interpreted with caution due to the limited sample size, these finding are nonetheless consistent with other research that has shown climate change skepticism to be reported mostly among Republicans, and only among a small proportion (18\%) of Americans as a whole [3]. Interestingly, most of those who refuted anthropogenic climate change nonetheless agreed that the climate is changing, which suggests an evolution of the discourse as it relates to climate change skepticism. That is, the skeptical viewpoint was once characterized by a disbelief that the climate was changing [21,58].

In identifying the general sources through which people obtain their news, a relatively higher proportion of the College Group ranked online sources among their top three news sources, with Facebook being ranked above newspapers as a top news source. That younger age groups report relatively increased use of social media as a primary news source is consistent with other recent polling [59-61]. This offers a potential opportunity as it relates to climate outreach to the youth (e.g., circulating climate news on Facebook).

While the questionnaire response rate for this study was high when administered in person during climate presentations or when surveying the public, the response rate online was very low. This is possibly due to people forgetting to follow up, thus highlighting the utility of spending extra time and resources to administer paper questionnaires by hand or using more active follow up methods (e.g., an email or phone reminder). Alternatively, asking audience members to take the online survey using their smart phones prior to the event was an effective way to make use of online surveys.

\subsection{Strengths and Limitations}

An important strength of this study is that it is grounded in community concerns and observations as well as principles of community-driven community-academic partnerships [62-66]. The geographic coverage, design, and implementation of this study, along with the ongoing development of a 
vision for a more informed and climate-resilient community were each guided by our partnership process. Community-academic partnerships characterized by ownership of action research agendas by community and academic partners have greater potential for informing the translation of research into action to promote community health and health equity [62,65]. An additional strength of this study is its geographic heterogeneity, which encompassed all major regions of the contiguous U.S., as well as our use of both quantitative and qualitative methods to answer research questions at the community level. The application of this qualitative aspect, including detailed one-on-one, in-person interactions with diverse groups of community members across the country, enabled us to obtain a more in-depth understanding of specific climate-related concerns and observations that may not be captured through questionnaires and other quantitative methods. Lastly, the framework of this study consisted of outreach efforts that resemble those that are actually practiced by community organizers, NGOs, and other outreach groups in the field. Thus, our evaluation of this project offers insights that can be readily applied by individuals and organizations during future climate outreach efforts.

Limitations of this study include small sample sizes for some of the geographic regions we surveyed, which resulted in an uneven geographic distribution of survey responses. However, detailed one-on-one, in-person interviews in the same geographic regions were conducted to help confirm the reliability and consistency of regional group response. Additionally, our analysis allows limited extrapolation since our sample population was mostly "climate concerned" individuals who tended to be Caucasian, highly educated, older, and Democrat. This analysis is limited in its ability to assess the views of the general public due to the limited sample size and spatial coverage of the General Public Group (mostly originating from CA, MI, and CO, and mostly Democrats). Finally, as it relates to college students, this group was different than the larger Presentation Group and the General Public group in more ways than just being in college and younger. This group tended to also be more ethnically diverse and consisted of more females. Thus, differences in college survey responses may be due in part to factors relating to gender and culture. Lastly, since our college sample was limited to certain universities and courses, the College Group may not fully reflect the greater college population.

\section{Conclusions}

Results from a national climate outreach campaign across the U.S. documented public attendance that was skewed towards college educated Caucasians who identified as Democrats. Climate-related changes that communities had observed included hotter temperatures, increased flooding, and impacts to species. One-on-one, in-person interviews reflected similar findings, but also highlighted climate impacts that are disproportionately affecting low-income communities and communities of color, such as heat-related mortality, elevated heating and cooling costs, gentrification, and extreme storm events. Climate adaptation strategies were underway, but were most prevalent among farmers, ecologists, and NGO workers, as opposed to the general public. "Future generations" was the most frequently ranked climate-related concern across a sample of 500 survey participants, with the economy, property value, infectious disease, and national security being least frequently ranked. Even among "climate-concerned" individuals, the majority were not civically engaged on the issue, suggesting that public concern over climate change does not necessarily translate to a high degree of political engagement. Among three survey groups, college students least frequently reported climate change as a top priority, and most frequently reported being "hopeful" about the problem, despite reporting a relatively lower frequency of civic engagement on the issue. Perspectives on climate change appeared to differ by political affiliation, with Republicans refuting anthropogenic climate change more than Democrats.

Supplementary Materials: The following are available online at http://www.mdpi.com//1/1/6/s1, Figure S1: Correlation plot (with Pearson correlation coefficient) of group size against the number of climate-related observations reported within each of 15 groups across the U.S., Figure S2: Local climate-related impacts reported during one-on-one interviews with 24 separate community members across the country. 
Author Contributions: Conceptualization, S.M.; methodology, S.M.; software, S.M.; formal analysis, S.M.; investigation, S.M. and A.S.; resources, S.M., A.S. and J.W.; data curation, S.M. and A.S.; writing-original draft preparation, S.M.; writing-review and editing, S.M., J.W. and S.H.; visualization, S.M.; project administration, S.M. and A.S.; funding acquisition, S.M. and A.S. All authors have read and agreed to the published version of the manuscript.

Funding: This research received no external funding.

Acknowledgments: We thank Victor Wong at the University of California, Irvine, for his assistance in preparing survey data for analysis, as well as Frank Martin at the Environmental Systems Research Institute, ESRI, for assisting with the collection of online survey data. We also thank Mark Moehlman and the many other community members who contributed to partially fund this field campaign, as well as the Citizens' Climate Lobby and others who helped organize educational community events around the country.

Conflicts of Interest: The authors declare no conflict of interest.

\section{References}

1. IPCC. Global Warming of $1.5^{\circ} \mathrm{C}$ : An IPCC Special Report on the Impacts of Global Warming of $1.5{ }^{\circ} \mathrm{C}$ above Pre-Industrial Levels and Related Global Greenhouse Gas Emission Pathways, in the Context of Strengthening the Global Response to the Threat of Climate Change, Sustainable Development, and Efforts to Eradicate Poverty; Intergovernmental Panel on Climate Change: Geneva, Switzerland, 2018; pp. 1-615.

2. U.S. Global Change Research Program. Fourth National Climate Assessment: Impacts, Risks, and Adaptation in the United States; U.S. Global Change Research Program: Washington, DC, USA, 2018.

3. Leiserowitz, A.; Maibach, E.; Roser-Renouf, C.; Smith, N. Global Warming's "Six Americas"; Yale Program on Climate Change Communication: New Haven, CT, USA, 2010.

4. Saad, L. Global Warming Concern at Three-Decade High in U.S.; Gallup, Inc.: Washington, DC, USA, 2017.

5. Leiserowitz, A.; Maibach, E.; Rosenthal, S.; Kotcher, J.; Bergquist, P.; Ballew, M.T.; Goldberg, M.; Gustafson, A. Climate Change in the American Mind: April 2019; Yale Program on Climate Change Communication: New Haven, CT, USA, 2019. [CrossRef]

6. Ballew, M.; Maibach, E.; Kotcher, J.; Bergquist, P.; Rosenthal, S.; Marlon, J.; Leiserowitz, A. Which Racial/Ethnic Groups Care Most about Climate Change? Yale Program on Climate Change Communication: New Haven, CT, USA, 2020.

7. Stokes, B.; Wike, R.; Carle, J. Global Concern about Climate Change, Broad Support for Limiting Emissions; Pew Research Center: Washington, DC, USA, 2015; pp. 1-12.

8. Pew Research Center. Economic Issues Decline Among Public's Policy Priorities; Pew Research Center: Washington, DC, USA, 2018.

9. Lachapelle, E. Communicating about Carbon Taxes and Emissions Trading Programs. In Oxford Research Encyclopedia of Climate Science; Oxford University Press: Oxford, UK, 2017. [CrossRef]

10. C40 Cities. How U.S. Cities Will Get the Job Done; C40: London, UK, 2016.

11. Mukherjee, I.; Howlett, M. Communicating about Climate Change with Policymakers. In Oxford Research Encyclopedia of Climate Science; Oxford University Press: Oxford, UK, 2020; pp. 1-19.

12. Shanahan, J. Agenda Building, Narratives, and Attention Cycles in Climate Change News Coverage. In Oxford Research Encyclopedia of Climate Science; Oxford University Press: Oxford, UK, 2017. [CrossRef]

13. Newman, T.P. Tracking the release of IPCC AR5 on Twitter: Users, comments, and sources following the release of the Working Group I Summary for Policymakers. Public Underst. Sci. 2017, 26, 815-825. [CrossRef] [PubMed]

14. Leiserowitz, A.A.; Myers, T.A.; Nisbet, M.C.; Maibach, E.W. A public health frame arouses hopeful emotions about climate change A Letter. Clim. Chang. 2012, 113, 1105-1112. [CrossRef]

15. Park, A. Everybody's Movement: Environmental Justice and Climate Change; Environmental Support Center: Washington, DC, USA, 2009; Volume 53.

16. Hamilton, L.C. Education, politics and opinions about climate change evidence for interaction effects. Clim. Chang. 2011, 104, 231-242. [CrossRef]

17. Nisbet, M.C.; Markowitz, E.M.; Kotcher, J. Winning the Conversation: Framing and Moral Messaging in Environmental Campaigns. In Talking Green: Exploring Contemporary Issues in Environmental Communications; Peter Lang Publishing: New York City, NY, USA, 2012; pp. 9-36. 
18. Maibach, E.W.; Kreslake, J.M.; Roser-Renouf, C.; Rosenthal, S.; Feinberg, G.; Leiserowitz, A.A. Do americans understand that global warming is harmful to human health? Evidence from a national survey. Ann. Glob. Health 2015, 81, 396-409. [CrossRef]

19. Bolsen, T.; Shapiro, M.A. The US News Media, Polarization on Climate Change, and Pathways to Effective Communication. Environ. Commun. 2018, 12, 149-163. [CrossRef]

20. Druckman, J.N. Communicating Policy-Relevant Science. PS Political Sci. Politics 2015, 48, 58-69. [CrossRef]

21. Lehmann, B.E. Many More Republicans Now Believe in Climate Change. Available online: https://www. scientificamerican.com/article/many-more-republicans-now-believe-in-climate-change/ (accessed on 16 November 2020).

22. Bolsen, T.; Shapiro, M.A. Strategic Framing and Persuasive Messaging to Influence Climate Change Perceptions and Decisions. In Oxford Research Encyclopedia of Climate Science; Oxford University Press: Oxford, UK, 2017. [CrossRef]

23. Bagley, K. About a Dozen Environment Reporters Left at Top 5 U.S. Papers. Available online: https:/insideclimatenews.org/news/20130114/new-york-times-dismantles-environmental-desk-climatechange-global-warming-journalism-newspapers-hurricane-sandy (accessed on 11 October 2020).

24. Hamilton, L.C. Who cares about polar regions? Results from a survey of U.S. public opinion. Arct. Antarct. Alp. Res. 2008, 40,671-678. [CrossRef]

25. UNESCO. Climate Change Education and Awareness. Available online: https://en.unesco.org/themes/ addressing-climate-change/climate-change-education-and-awareness (accessed on 16 November 2020).

26. UNESCO. Green Citizens. Available online: https://www.unescogreencitizens.org/ (accessed on 16 November 2020).

27. CCL. Climate Advocate Training. Available online: https://citizensclimatelobby.org/climate-advocatetraining/\#climateadvocatetraining (accessed on 11 October 2020).

28. CRP. Become a Climate Reality Leaders. Available online: https://www.climaterealityproject.org/training (accessed on 16 November 2020).

29. United Nations Environment Programme's Division of Environmental Law and Conventions. Raising Awareness of Climate Change; United Nations Environment Programme's Division of Environmental Law and Conventions: Geneva, Switzerland, 2006; ISBN 4122917824.

30. Britten, N. Qualitative Interviews in Healthcare, 2nd ed.; BMJ Books: London, UK, 1999.

31. Gill, P.; Stewart, K.; Treasure, E.; Chadwick, B. Methods of data collection in qualitative research: Interviews and focus groups. Br. Dent. J. 2008, 204, 291-295. [CrossRef]

32. Burnard, P.; Gill, P.; Stewart, K.; Treasure, E.; Chadwick, B. Analysing and presenting qualitative data. Br. Dent. J. 2008, 204, 429-432. [CrossRef]

33. Stewart, K.; Gill, P.; Treasure, E.; Chadwick, B. Understandings about Food among 6-11 Year Olds in South Wales. Food Cult. Soc. 2006, 9, 317-336. [CrossRef]

34. Braun, V.; Clarke, V. Using thematic analysis in psychology. Qual. Res. Psychol. 2006, 3, 77-101. [CrossRef]

35. Hsieh, H.F.; Shannon, S.E. Three approaches to qualitative content analysis. Qual. Health Res. 2005, 15, 1277-1288. [CrossRef] [PubMed]

36. Noble, H.; Smith, J. Issues of validity and reliability in qualitative research. Evid. Based Nurs. 2015, 18, 34-35. [CrossRef] [PubMed]

37. NOAA. Weather Fatalities. Available online: https://www.nws.noaa.gov/om/hazstats.shtml (accessed on 10 November 2020).

38. Taylor, D.E. The State of Diversity in Environmental Organizations; School of Natural Resources and Environment, University of Michigan: Ann Arbor, MI, USA, 2014.

39. Metz, D.; Weigel, L. Key Findings from Recent Opinion Research on "Ecosystem Services"; FM3 Research: Los Angeles, CA, USA, 2010.

40. CLCV. Asian American Environmentalists: An Untapped Power for Change in California; CLCV: Oakland, CA, USA, 2009.

41. Robert, D.; Bullard, B.W. (Eds.) Race, Place, and Environmental Justice after Hurricane Katrina; Westview Press: Boulder, CO, USA, 2009.

42. Karaye, I.M.; Thompson, C.; Horney, J.A. Evacuation Shelter Deficits for Socially Vulnerable Texas Residents During Hurricane Harvey. Health Serv. Res. Manag. Epidemiol. 2019, 6. [CrossRef] 
43. Shonkoff, S.B.; Morello-Frosch, R.; Pastor, M.; Sadd, J. The climate gap: Environmental health and equity implications of climate change and mitigation policies in California-A review of the literature. Clim. Change 2011, 109, 485-503. [CrossRef]

44. U.S. National Oceanic and Atmospheric Administration. U.S. Billion-Dollar Weather E Climate Disasters 1980-2019; NOAA National Centers for Environmental Information: Washington, DC, USA, 2019; pp. 1-15.

45. Barnett, J. Security and climate change. Glob. Environ. Chang. 2003, 13, 7-17. [CrossRef]

46. UNHCR. Frequently Asked Questions on Climate Change and Disaster Displacement. Available online: https://www.unhcr.org/en-us/news/latest/2016/11/581f52dc4/frequently-asked-questions-climate-changedisaster-displacement.html (accessed on 11 October 2020).

47. The White House. The National Security a Changing Climate; The White House: Washington, DC, USA, 2015.

48. Hagel, C. Conference of Defense Ministers of the Americas. In Proceedings of the USDOD U.S. Department of Defense, Arequipa, Peru, 13 October 2014; pp. 1-4.

49. Dantas-Torres, F. Climate change, biodiversity, ticks and tick-borne diseases: The butterfly effect. Int. J. Parasitol. Parasites Wildl. 2015, 4, 452-461. [CrossRef]

50. Rosenberg, R.; Lindsey, N.P.; Fischer, M.; Gregory, C.J.; Hinckley, A.F.; Mead, P.S.; Paz-Bailey, G.; Waterman, S.H.; Drexler, N.A.; Kersh, G.J.; et al. Vital Signs: Trends in Reported Vectorborne Disease Cases-United States and Territories, 2004-2016. MMWR Morb. Mortal. Wkly. Rep. 2018, 67, 496-501. [CrossRef]

51. Zaval, L.; Cornwell, J.F.M.; Zaval, L.; Cornwell, J.F.M. Cognitive Biases, Non-Rational Judgments, and Public Perceptions of Climate Change. In Oxford Research Encyclopedia of Climate Science; Oxford University Press: Oxford, UK, 2016. [CrossRef]

52. Singh, S.P.; Swanson, M. How issue frames shape beliefs about the importance of climate change policy across ideological and partisan groups. PLoS ONE 2017, 12, e0181401. [CrossRef]

53. Spence, A.; Poortinga, W.; Butler, C.; Pidgeon, N.F. Perceptions of climate change and willingness to save energy related to flood experience. Nat. Clim. Chang. 2011, 1, 46-49. [CrossRef]

54. Hultsch, D.F.; Bortner, R.W. Personal time perspective in adulthood: A time-sequential study. Dev. Psychol. 1974, 10, 835-837. [CrossRef]

55. Leiserowitz, A.; Akerlof, K. Race, Ethnicity and Public Responses to Climate Change; Yale Program on Climate Change Communication: New Haven, CT, USA, 2010.

56. Fesenfeld, L.P.; Rinscheid, A. Emphasizing Urgency of Climate Change No Silver Bullet to Increase Policy Support. One Earth 2020. [CrossRef]

57. Wiest, S.L.; Raymond, L.; Clawson, R.A. Framing, partisan predispositions, and public opinion on climate change. Glob. Environ. Chang. 2015, 31, 187-198. [CrossRef]

58. Van der Linden, S.; Leiserowitz, A.; Rosenthal, S.; Maibach, E. Inoculating the Public against Misinformation about Climate Change. Glob. Chall. 2017, 1, 1600008. [CrossRef] [PubMed]

59. Vogels, E.A. Millennials Stand out for Their Technology Use, but Older Generations also Embrace Digital Life. Available online: https://www.pewresearch.org/fact-tank/2019/09/09/us-generations-technology-use/ (accessed on 11 November 2020).

60. Anderson Monica, J.J. Teens, Social Media \& Technology. 2018. Available online: http: //www.pewinternet.org/2018/05/31/teens-social-media-technology-2018/?utm_source=pocket\&utm_ medium=email\&utm_campaign=pockethits (accessed on 10 November 2020).

61. Shearer, E. Social Media Outpaces Print Newspapers in the U.S. as a News Source. Available online: http://www.pewresearch.org/fact-tank/2018/10/19/5-charts-on-global-views-of-china/ (accessed on 10 November 2020).

62. González, R. The Spectrum of Community Engagement to Ownership; Movement Strategy Center: Oakland, CA, USA, 2019.

63. Developing and Maintaining Partnerships with Communities. Methods for Community-Based Participatory Research for Health; Israel, B.A., Eng, E., Schulz, S.J., Parker, E.A., Eds.; Jossey-Bass: John Wiley \& Sons, Inc.: Hoboken, NJ, USA, 2005; pp. 31-51. ISBN 978-1-1180-2186-6.

64. Lebrón, A.M.W.; Torres, I.R.; Valencia, E.; Dominguez, M.L.; Garcia-Sanchez, D.G.; Logue, M.D.; Wu, J. The state of public health lead policies: Implications for urban health inequities and recommendations for health equity. Int. J. Environ. Res. Public Health 2019, 16, 1064. [CrossRef] 
65. Wolff, T.; Minkler, M.; Wolfe, S.M.; Berkowitz, B.; Bowen, L.; Butterfoss, F.D.; Christens, B.D.; Francisco, V.T.; Himmelman, A.T.; Lee, K.S. Collaborating for Equity and Justice: Moving Beyond Collective Impact. Nonprofit Q. 2017, 9, 42-53.

66. Masri, S.; LeBrón, A.; Logue, M.; Valencia, E.; Ruiz, A.; Reyes, A.; Lawrence, J.M.; Wu, J. Social and spatial distribution of soil lead concentrations in the City of Santa Ana, California: Implications for health inequities. Sci. Total Environ. 2020, 743, 140764. [CrossRef]

Publisher's Note: MDPI stays neutral with regard to jurisdictional claims in published maps and institutional affiliations.

(C) 2020 by the authors. Licensee MDPI, Basel, Switzerland. This article is an open access article distributed under the terms and conditions of the Creative Commons Attribution (CC BY) license (http://creativecommons.org/licenses/by/4.0/). 